\title{
Clinical differences between eosinophilic and non- eosinophilic acute exacerbation of chronic obstructive pulmonary disease (AECOPD), a multicenter cross-sectional study
}

\section{Guangming Dai}

First People's Hospital of Suining City

\section{Yajuan Ran}

The second affiliated hospital of Chongqing medical university https://orcid.org/0000-0002-5628-5397

\section{Jiajia Wang}

The second affiliated hospital of Chongqing medical university

\section{Xingru Chen}

The second affiliated hospital of Chongqing medical university

\section{Junnan Peng}

The second affiliated hospital of Chongqing medical university

\section{Xinglong Li}

Zhujiang Hospital of Southern Medical University

\section{Huojin Deng}

Zhujiang Hospital of Southern Medical University

\section{Min Xiao}

West China Hospital of Sichuan University

Tao Zhu ( $\sim$ zhutao063020@163.com )

https://orcid.org/0000-0001-9622-2721

\section{Research}

Keywords: Acute exacerbation of chronic obstructive pulmonary disease (AECOPD), Eosinophils (EOS), Lymphocytes\%, Neutrophils\%, Procalcitonin (PCT)

Posted Date: May 14th, 2020

DOI: https://doi.org/10.21203/rs.3.rs-27485/v1

License: (c) (i) This work is licensed under a Creative Commons Attribution 4.0 International License. Read Full License 


\section{Abstract}

Background AECOPD is highly heterogeneous with respect to etiology and inflammation. COPD with higher blood eosinophils is associated with increased readmission rates and better corticosteroid response. However, the clinical features of eosinophilic AECOPD aren't well explored. Then, the aim of this study was to investigate the clinical differences between eosinophilic and non-eosinophilic AECOPD.

Methods A total of 643 AECOPD patients were enrolled in this multicenter cross-sectional study. Finally, 455 were included, 214 in normal eosinophils AECOPD (NEOS-AECOPD) group, 63 in mild increased eosinophils AECOPD (MEOS-AECOPD) group, and 138 in severe increased eosinophils AECOPD (SEOS-AECOPD) group. Then, demographic data, underlying diseases, symptoms, and laboratory findings were collected. Multiple logistic regression was performed to identify the independent factors associated with blood EOS. Correlations between blood EOS and its associated independent factors were evaluated.

Results The significant differences in 19 factors, including underlying disease, clinical symptom, and laboratory parameters, were identified by univariate analysis. Subsequently, multiple logistic regression revealed that lymphocytes\%, neutrophils\% (NS\%), procalcitonin (PCT), and anion gap (AG) were associated with blood EOS in AECOPD. Both blood EOS counts and EOS\% significantly correlated with lymphocytes\%, NS\%, PCT, and AG.

Conclusions The blood EOS was independently associated with lymphocytes $\%$, NS\%, PCT, and AG in AECOPD patients. Lymphocytes\% was lower, and, NS\%, PCT, and AG were higher in eosinophilic AECOPD. Our results indicate that viral dominant infections probably were the major etiology of eosinophilic AECOPD. Non-eosinophilic AECOPD was more likely associated with bacterial dominant infections. The systemic inflammation in non-eosinophilic AECOPD was more severe.

\section{Background}

COPD is the most common chronic pulmonary disorder. It is found that the prevalence of COPD is gradually increasing in recent decades [1-3]. Wang $C$ et al showed that the prevalence of COPD was 8.6\%, about 99.9 million patients, in mainland China [2]. It is estimated that about 3.2 million people died from COPD worldwide in 2015 [1]. Globally, COPD is going to be the third leading cause of death by diseases in recent years $[3,4]$. Meanwhile, COPD is also a highly heterogeneous disease $[5,6]$. In clinical practice, the response and outcome of the treatments were different individually. Most clinicians realized the importance and needs of individual and target therapies in COPD.

Although amount of potential biomarkers [7], from inflammatory mediators/proteins[8] to miRNAs[9, 10], DNA methylation CpG sites [11, 12], single nucleotide polymorphisms (SNPs) [13, 14], and metabolites [15, 16], were found, blood eosinophil (EOS) is considered to be a stable, available and acceptable marker in clinical practice $[17,18]$. Classically, COPD is considered as a Th1 dependent chronic airway inflammation. Neutrophils (NS), macrophages, and Th1 cells were the major immunological cells in COPD, whereas eosinophils (EOS), B cells, and Th2 cells were essential for asthma $[3,19,20]$. However, mounting evidence reported that sputum and blood eosinophils also increased in a subset of COPD patients [17, $21,22]$. Several studies showed that higher blood eosinophil counts were associated with an increased risk of readmission, severe lung function impairment, and longer length hospital stay (LHS) in COPD [23-26]. Some studies identified that inhaled corticosteroid (ICS) plus long-acting $\beta 2$-agonist (LABA) and ICS plus LABA plus long-acting muscarinic antagonist (LAMA) brought more benefits in eosinophilic (EOS) COPD than in non-eosinophilic COPD [27, 28]. Therefore, increased blood EOS was considered to be a "treatable trait" of COPD $[18,24]$. Nevertheless, the clinical features of eosinophilic hospitalized AECOPD are still not well studied. Thus, the aim of this study was to investigate the clinical differences between eosinophilic and non-eosinophilic AECOPD.

Additionally, the best cut-off value of blood EOS is still not determined. With the cut-off of EOS $\% \geq 2 \%$ and/or EOS counts $\geq 200$ cells/ $\mu \mathrm{L}$, Couillard S et al showed that the risk of 12-month COPD-related readmission in eosinophilic AECOPD was

Page $2 / 13$ 
increased and LHS was not different, compared with non-eosinophilic AECOPD [21]. With the cut-off value of $300 \mathrm{cells} / \mu \mathrm{L}$, Qi YJ et al found that sputum microbiome richness and plasma IL-6 level in eosinophilic AECOPD decreased more significantly than in non-eosinophilic AECOPD, after 7 days treatments [29]. Cheng SL et al demonstrated that the ICS response in COPD with EOS\% > 3\% was better than non-eosinophilic COPD [30]. Therefore, in our study, based on both blood EOS counts and EOS\%, the patients with AECOPD were divided into 3 subgroups (Figure 1).

\section{Methods}

\subsection{Study design and population}

This multicenter cross-sectional study was performed at respiratory departments of two tertiary hospitals in China between January 2017 and January 2020. This study was approved by the Research Ethics Committees of our hospital (No. 2019-23) in accordance with the Declaration of Helsinki. Informed consent was obtained from all the patients by the responsible physician or an appropriately trained staff member. Standard care and treatments were provided in our study according to current clinical guidelines $[3,5]$.

\subsection{Sample size determinations}

As for sample size, a minimum total of 159 (53 in each group) was required to detect at least a $25 \%$ difference in effect size for an $80 \%$ power, assuming $a=0.05$ and allocation ratio $=1: 1: 1$. Furthermore, $20 \%$ more (64 in each group) patients were recruited.

\subsection{Inclusion and exclusion criteria}

The inclusion criterion was COPD exacerbation requiring hospitalization. Exclusion criteria were as follows: age $<40$ years, non-respiratory failure patients without lung function test, active pulmonary tuberculosis (TB), asthma, bronchiectasis, pneumoconiosis, interstitial lung diseases (ILDs), other chronic lung diseases, dysphagia and aspiration, dementia, hospital-acquired pneumonia (HAP), immunocompromised status (organ transplant, system steroid use within the last 2 weeks, immunosuppressive agents use within the last 4 weeks, and HIV infection), history of malignant diseases, renal failure, and liver failure. A total of 643 patients with hospitalized AECOPD were enrolled. Finally, 455 were included, 214 in normal eosinophils AECOPD (NEOS-AECOPD) group, 63 in mild increased eosinophils AECOPD (MEOS-AECOPD) group, and 138 in severe increased eosinophils AECOPD (SEOS-AECOPD) group (Figure 1).

\subsection{Definitions}

According to the COPD guidelines [3,5], the diagnosis of COPD was confirmed by the pulmonologists, based on noxious stimuli exposure history, risk factors, clinical symptoms, and spirometry (FEV1/FVC\% $<0.7$ after bronchodilator inhalation). AECOPD was defined as an event in the natural course of the disease characterized by acute changes in clinical symptoms beyond normal day-to-day variation, resulting in additional therapy $[3,5]$. Both blood EOS counts and EOS\% were considered to set the cut-off values of EOS. In this study, normal eosinophils AECOPD (NEOS-AECOPD) was defined as AECOPD with EOS\% $<2 \%$ and EOS counts $<200$ cells/ $\mu \mathrm{L}$. Mild increased eosinophils AECOPD (MEOS-AECOPD) was defined as AECOPD with EOS $\% 2 \%-2.99 \%$ and/or EOS counts $200-299$ cells/ $\mu$ l. Severe increased eosinophils AECOPD (SEOS-AECOPD) was defined as AECOPD with EOS\% $\geq 3 \%$ and/or EOS counts $\geq 300$ cells/ $\mu \mathrm{L}$. The ex-smoker was defined as abstaining from smoking $\geq 6$ months. Neutrophils-to-lymphocytes ratio (NLR) was defined as neutrophils divided by lymphocytes in the blood.

\subsection{Data collection}

In our study, demographic data, underlying diseases, comorbid conditions, symptoms, and length of hospital stay (LHS) were recorded and collected. The blood samples for laboratory tests and lung function tests were all collected and 
performed within $24 \mathrm{~h}$ after admission. However, for safety reason and cooperation concerns, the spirometer test wasn't performed in patients with respiratory failure. All patients underwent CT scans within 48 hours of hospitalization and the results were reviewed by one independent radiologist and one pulmonologist in each hospital.

\subsection{Statistical analysis}

Data were analyzed using SPSS 20.0 software (SPSS Inc., Chicago, IL, USA). Continuous variables were expressed as the Mean \pm Standard Deviation (SD), and categorical data were expressed as frequencies. The data distribution was analyzed by Kolmogorov-Smirnov test. Continuous variables with normal distribution were analyzed by one-way ANOVA with LSD and SNK's post-hoc test. Continuous variables with abnormal distribution and ordinal variables were measured by KruskalWallis $\mathrm{H}$ test. Chi square test or Fisher's exact test was used to analyze categorical variables. Multiple logistic regression analysis was performed to investigate the independent risk factors associated with blood eosinophils in AECOPD patients. Spearman rank correlation coefficient was calculated to analyze correlations. A threshold of $p<0.05$ was considered to be significant.

\section{Results}

\subsection{Baseline characteristics of AECOPD patients.}

A total of 643 hospitalized patients with AECOPD were enrolled, and 188 patients were excluded (Figure 1). At last, 214 (47.03\%) NEOS-AECOPD patients, 63 (13.85\%) MEOS-AECOPD patients, and 178 (39.12\%) SEOS-AECOPD patients were eligible. The ratio of eosinophilic AECOPD (MEOS-AECOPD+SEOS-AECOPD) was $52.97 \%$. The demographic data of the patients was shown in Table 1. The rate of CTD was significantly higher in SEOS-AECOPD.

\subsection{Clinical features and laboratory data of AECOPD patients.}

As shown in Table 2, the rates of fever and mechanical ventilation (MV), white blood cells (WBCs), neutrophils (NS), NS\%, lymphocytes\%, NLR, procalcitonin (PCT), C-reaction protein (CRP), erythrocyte sedimentation rate (ESR), anion gap (AG), serum sodium $(\mathrm{Na})$, serum potassium $(\mathrm{K})$, serum calcium $(\mathrm{Ca})$, serum magnesium $(\mathrm{Mg})$, blood urea nitrogen (BUN), direct bilirubin (DBIL), and LHS were significantly different among 3 groups.

\subsection{Multiple logistic regression analysis in AECOPD patients.}

To explore independent factors associated with blood eosinophils in AECOPD patients, multiple logistic regression analysis was performed. In multiple logistic regression model, 19 factors significantly association with blood eosinophils in univariate analysis, including the rates of CTD, fever, and MV, WBC, NS, NS\%, lymphocytes\%, NLR, PCT, CRP, ESR, AG, serum $\mathrm{Na}$, serum $\mathrm{K}$, serum $\mathrm{Ca}$, serum Mg, BUN, DBIL, and LHS, were included. Multiple logistic regression analysis revealed that lymphocytes\%, NS\%, PCT, and AG were independently associated with blood eosinophils in AECOPD patients (Table $3)$.

\subsection{Correlations between blood EOS counts/EOS\% and lymphocytes\%, NS\%, PCT, AG in AECOPD patients.}

Since lymphocytes \%, NS\%, PCT, and AG were independently associated with blood eosinophils in AECOPD patients. Then, their correlations with blood EOS counts and EOS\% were explored. The significant correlations were found between blood EOS counts and lymphocytes\%, NS\%, PCT, AG, and, between blood EOS\% and lymphocytes\%, NS\%, PCT, AG in patients with AECOPD (Table 4). Among them, lymphocytes\% was positively, and, NS\%, PCT, and AG were negatively correlated with blood EOS counts and EOS\%.

\section{Discussion}


In this multicenter cross-sectional study, the clinical features of patients with eosinophilic AECOPD were explored. Based on the two cut-off values of blood EOS, the patients were divided into 3 subgroups, normal eosinophils AECOPD (NEOSAECOPD) was defined as EOS $\%<2 \%$ and EOS counts $<200$ cells $/ \mu \mathrm{L}$, mild increased eosinophils AECOPD (MEOSAECOPD) was defined as EOS\% 2\%-2.99\% and/or EOS counts 200-299 cells/ $\mu \mathrm{l}$, and severe increased eosinophils AECOPD (SEOS-AECOPD) was defined as EOS $\% \geq 3 \%$ and/or EOS counts $\geq 300$ cells/ $\mu \mathrm{L}$. Our results showed that lymphocytes\%, $\mathrm{NS} \%, \mathrm{PCT}$, and AG were the independent factors associated with blood EOS in AECOPD patients. Then, these results indicate that viral dominant infection probably was related to eosinophilic AECOPD. And, non-eosinophilic AECOPD was more likely associated with bacterial dominant infections.

As the most common lung disorder, the prevalence of COPD is still increasing in recent years $[2,3,5]$. It was estimated that the prevalence of COPD was $11.7 \%$ (8.4\%-15.0\%) and the COPD case number was about 384 million globally in 2010 [3, 4]. Wang, $\mathrm{C}$ et al showed that the overall prevalence of COPD in mainland China was $8.6 \%(95 \% \mathrm{Cl} 7.5-9.9)$ in $\geq 40$ years-old population, namely about 99.9 (95\% Cl 76.3-135.7) million cases [2, 3]. Simultaneously, COPD is a chronic disease with high mortality and disability. It was reported that about 3 million people dead from COPD every year [3, 31]. Patel JG et al showed that COPD caused average of 5 more days of work absence and $\$ 641$ short-term disability associated extra costs each year in the USA [32]. It was estimated that the global years lived with disability (YLDs) of COPD was about 29.4 million in 2010 [33].

Nevertheless, COPD is a highly heterogeneous disease, with significantly differences in treatment response and outcomes in patients. Mounting evidence suggested that individual therapy and target therapy are the major trends of COPD in the future. Then, to explore and differentiate the phenotypes of COPD is valuable in clinical practice. In recent years, amount of studies showed that blood eosinophil is an effective, stable, and available biomarker in COPD, which can be used to define the phenotypes of COPD [17, 25, 34, 35]. However, the cut-off value of blood EOS is still in debate, ranging from 150 to 400 cells/ $\mu \mathrm{L}$ and/or $2 \%$ to $4 \%$ in different studies $[17,18,22,24,25,34-36]$. Then, in this study, both 200 cells/ $\mu \mathrm{L}$ and 300 cells/ $\mu \mathrm{L}$, and, $2 \%$ and $3 \%$ were considered as the cut-off values of blood EOS counts and EOS\% in AECOPD patients (Figure 1). According to demographic data, no differences in sex, age, BMI, smoking status, lung functions (GOLD stages), and most of comorbidities and complications were found among 3 groups (Table 1). Only connective tissue disease (CTD) was found significant differently among 3 groups. The rate of CTD in SEOS-AECOPD was higher than NEOS- and MEOSAECOPD group (Table 1). These results indicate that sex, BMI, smoking, and lung function were not associated with blood EOS in AECOPD patients.

The correlations between blood EOS and EOS in the lungs (induced sputum, BAL, and tissues) were still in controversy. Many studied showed that blood EOS was considered to be a reasonably good predictor of EOS in airways in COPD patients [22, 37, 38]. Eltboli $O$ et al showed that the strong correlations between blood EOS\% and the submucosal eosinophil counts $(r=0.57)$ and reticular basement membrane (RBM) thickness $(r=0.59)$ were found in COPD [37]. Kolsum $U$ et al reported that compared with COPD with blood EOS < 150 cells $/ \mu \mathrm{L}$, EOS\% in induced sputum, BALF, and submucosa were all significantly increased in COPD with blood EOS $>300$ cells/ $\mu \mathrm{L}$ [38]. Nevertheless, several studies found that the correlation between lung tissue and blood EOS was not very well $[36,39]$. Turato $\mathrm{G}$ et al explored the correlations between blood eosinophils and central airways, peripheral airways, and lung parenchyma, from COPD patients underwent lung resection for solitary pulmonary nodules without additional complications [36]. Initially, no difference in the eosinophil number in central airways, peripheral airways, and lung parenchyma was observed in COPD, and, pulmonary eosinophil counts weren't associated with disease severity. Subsequently, they revealed that the correlations between blood eosinophils and any of the three lung compartments were not significant. Meanwhile, in a randomized, double-blind, placebo-controlled trial (RCT), EOS counts and EOS\% in induced sputum were markedly reduced after 16 weeks of roflumilast (a PDE4 inhibitor) treatment in COPD [39]. However, blood eosinophil counts were not changed by roflumilast. Whatever, the significant differences in some aspects of clinical characteristics and outcomes were identified between eosinophilic and non-eosinophilic AECOPD patients by many studies [17, 20, 23-25, 30, 35, 40]. Mounting evidence showed 
that increased blood EOS was associated with higher risk readmission, severe lung function impairment, longer LHS and survival time, and better ICS response in COPD patients [23-25]. Nevertheless, the clinical features, particularly laboratory parameters, of eosinophilic AECOPD were still not well studied. In this study, commonly used laboratory parameters and tests, including blood routine, PCT, ESR, CRP, ABG, serum electrolytes, liver function test, and renal function test, were included. Our data showed that the rates of fever and MV, WBC, NS, NS\%, lymphocytes\%, NLR, PCT, CRP, ESR, AG, serum $\mathrm{Na}$, serum K, serum Ca, serum Mg, BUN, DBIL, and LHS were significantly different among 3 groups (Table 2).

Subsequently, 19 variables with significantly differences in univariate analysis were included in multiple logistic regression model. We found that lymphocytes\%, NS\%, PCT, and AG were independently associated with blood EOS in AECOPD patients.

Meanwhile, as shown in Table 4, lymphocytes\% was positively, and, NS\%, PCT, and AG were negatively correlated with both blood EOS counts and EOS\% in AECOPD. In this study, according to the criteria, asthma was strictly excluded, which was considered to be the most commonly confounder of the COPD study $[18,23,40]$. Meanwhile, patients with recent system steroid use and immunosuppressive agents use were also excluded. These data indicate that inflammatory types were significantly different between eosinophilic and non-eosinophilic AECOPD patients. Namely, eosinophils and lymphocytes were the major inflammatory cells in eosinophilic AECOPD, and, neutrophils were the dominant inflammatory cells in noneosinophilic AECOPD. Meanwhile, it is well known that respiratory tract infection is the leading etiology of acute exacerbation in COPD $[3,35,41-43]$. Among them, bacteria and viruses are the most common pathogens. In a prospective observational study, Bafadhel $\mathrm{M}$ et al showed that $55 \%$ and $29 \%$ of acute exacerbation were related to bacterial and viral infection in COPD [43]. Meanwhile, Papi A et al demonstrated that bacterial and/or viral infection was found in $78.1 \%$ (29.7\% bacterial, $23.4 \%$ viral, $25 \%$ viral/bacterial coinfection) of AECOPD patients [41]. Simultaneously, several studies showed that airway eosinophilic inflammation was related to viral infection in AECOPD [35, 41]. Additionally, it is confirmed that blood neutrophils and PCT are the biomarkers of bacterial infection in COPD [44]. In a meta-analysis, Ni W et al showed that the sensitivity and specificity of PCT in diagnosing bacterial infections were 0.60 and 0.76 , and AUC of ROC curve was 0.77 [44]. Ergan B et al found that compared with culture-negative patients, PCT was markedly increased in culture-positive patients in AECOPD [45]. Their data also showed that $0.25 \mathrm{ng} / \mathrm{ml}$ was the optimal cut-off value, with $63 \%$ sensitivity, 67\% specificity, and 0.73 AUC, to predict bacterial infection in AECOPD. Collectively, our results suggested that viral and virus dominant infections probably were the major etiology of eosinophilic acute exacerbation in COPD. Then, non-eosinophilic acute exacerbation in COPD was more likely associated with bacterial and bacterial dominant infection.

Additionally, NS\%, PCT, and AG were negatively correlated with blood EOS in AECOPD (Table 4). And, AG, PCT, and NS\% in SEOS-AECOPD were significantly lower than NEOS-AECOPD and MESO-AECOPD (Table 2). No difference in metabolic acidosis was observed in three groups (Table 1). Circulation and tissue hypoperfusion are associated with severe infection in clinical practice. Generally, hypoperfusion-induced hyperlactacidemia is the major reason for increased AG in infection diseases patients without renal failure and ketoacidosis. Durmuş $U$ et al revealed that lactate clearance in AEOPD patients with hospitalization (severe patients) was significantly lower than in AECOPD patients without hospitalization (non-severe patients) [46]. Taken together, these results indicate that bacterial infection and systemic inflammation in non-eosinophilic AECOPD were more severe than in eosinophilic AECOPD.

Due to low positive rates of sputum cultures, specimen contamination, and airway bacterial colonization in COPD patients, the pathogen results were not included to reduce biases and confounders, which was also one of the major limitations of our current study. Therefore, the direct correlations between pathogen types and blood eosinophils were not evaluated. The main strength of our study is that relatively comprehensive laboratory data were collected, which accurately evaluated the severity and complications of the underlying diseases. Particularly, chest HRCT scan was performed in each patient, which effectively promoted the diagnosis accuracy and excluded most other lung diseases. Furthermore, the different cut-off values of blood EOS were considered, making our data more convincible. 


\section{Conclusions}

Collectively, our results indicated that lymphocytes\%, NS\%, PCT, and AG were the independent factors associated with blood EOS in AECOPD patients. Viral and viral dominant infections probably were the major etiology of eosinophilic AECOPD. Then, non-eosinophilic AECOPD was more likely associated with bacterial and bacterial dominant infections. The systemic inflammation in non-eosinophilic AECOPD was more severe than in eosinophilic AECOPD. Nevertheless, further study with high sensitivity and specificity in pathogen tests, such as bronchoscope, should be carried out to validate this result.

\section{Abbreviations}

AECOPD: chronic obstructive pulmonary disease); AB: Actual base; ABG: Air blood gas; AG: anion gap; ALB: Albumin; ALT: Alanine aminotransferase; AST: Aspartate aminotransferase; BUN: Blood urea nitrogen; Ca: Calcium; Cr: Creatinine; CRP: Creaction protein; CTD: Connective tissue disease; DBIL: Direct bilirubin; EOS: eosinophil; ESR: Erythrocyte sedimentation rate; FEV1: Forced expiratory volume at 1 second; FVC: forced vital capacity; HAP: hospital-acquired pneumonia; Hb: Hemoglobin; IBIL: Indirect bilirubin; K: Potassium; ICS: inhaled corticosteroid; ILDs: interstitial lung diseases; IPPV: Invasive positive pressure ventilation; LHS: longer length hospital stay; MEOS-AECOPD: mild increased eosinophils AECOPD; Mg: Magnesium; MV: Mechanical Ventilation; Na: Sodium; NEOS-AECOPD: normal eosinophils AECOPD; NIPPV: Non-invasive positive pressure ventilation; NLR: Neutrophils-to-lymphocytes ratio; NS: neutrophils; OI: Oxygen index; PCT: procalcitonin; PE: Pleural effusion; PLTs: Platelets; RBCs: Red blood cells; RBG: Random blood glucose; SB: Standard base; SEOSAECOPD: severe increased eosinophils AECOPD; SNPs: single nucleotide polymorphisms; TB: tuberculosis; WBCs: White blood cells

\section{Declarations}

\section{Acknowledgements}

We want to express our sincere appreciation to all the patients who participated in the study.

\section{Authors' Contributions}

All authors read and approved the final manuscript. Tao Zhu conceived the study design. Guangming Dai, Jiajia Wang, Yajuan Ran, Xingru Chen, Junnan Peng, and Xinglong Li collected the data. Guangming Dai, Yajuan Ran, Jiajia Wang, Huojin Deng, Min Xiao, and Tao Zhu analyzed and interpreted the data. Guangming Dai, Yajuan Ran, Jiajia Wang, Min Xiao, and Tao Zhu drafted the manuscript. All authors read and approved the final manuscript.

\section{Funding}

This study was supported by Youth fund of National Natural Science Foundation of China (81801484), Natural Science Foundation of Guangdong Province (2017A030310286), Scientific Research Project of Guangzhou (201707010282), and Science and Technology Planning Project of Guangdong Province (2014A020212627 and 2016A020215099).

\section{Availability of data and materials}

Not applicable.

\section{Ethics approval and consent to participate}

This study was approved by the Research Ethics Committees of our hospital (No. 2019-23) in accordance with the Declaration of Helsinki. Informed consent was obtained from all the patients by the responsible physician or an 
appropriately trained staff member.

\section{Consent for publication}

Not applicable.

\section{Competing interests}

The authors declare no conflict of interest.

\section{Author details}

${ }^{1}$ Respiratory Department, First People's Hospital of Suining City, 629000, Suining, Sichuan, China; ${ }^{2}$ Pharmacy Department, Second Affiliated Hospital of Chongqing Medical University, 400010 Chongqing, China; ${ }^{3}$ Rheumatology Medicine, Second Affiliated Hospital of Chongqing Medical University, 400010 Chongqing, China; ${ }^{4}$ Respiratory Medicine, Second Affiliated Hospital of Chongqing Medical University, 400010, Chongqing, China; ${ }^{5}$ Respiratory Medicine, ZhuJiang Hospital of Southern Medical University, Guangzhou 510280, China; ${ }^{6}$ Respiratory Medicine, and Division of Pulmonary Diseases, State Key Laboratory of Biotherapy of China, West China Hospital of Sichuan University, Chengdu 610041, China

\section{References}

1. Collaborators GCRD: Global, regional, and national deaths, prevalence, disability-adjusted life years, and years lived with disability for chronic obstructive pulmonary disease and asthma, 1990-2015: a systematic analysis for the Global Burden of Disease Study 2015. Lancet Respir Med 2017, 5:691-706.

2. Wang C, Xu J, Yang L, Xu Y, Zhang X, Bai C, Kang J, Ran P, Shen H, Wen F, et al: Prevalence and risk factors of chronic obstructive pulmonary disease in China (the China Pulmonary Health [CPH] study): a national cross-sectional study. Lancet 2018, 391:1706-1717.

3. GOLD: Global strategy for the diagnosis, management, and prevention of chronic obstructive pulmonary disease (Revised 2018). https://goldcopdorg/ 2018.

4. Adeloye D, Chua S, Lee C, Basquill C, Papana A, Theodoratou E, Nair H, Gasevic D, Sridhar D, Campbell H, et al: Global and regional estimates of COPD prevalence: Systematic review and meta-analysis. J Glob Health 2015, 5:020415.

5. Chronic Obstructive Pulmonary Disease Committee. Respiratory Society CMA: [Guideline for diagnosis and treatment of chronic obstructive pulmonary disease (Version 2013)]. Chin J Tuberc Respir Dis 2013, 4:255-264.

6. Agustí A, Celli B, Faner R: What does endotyping mean for treatment in chronic obstructive pulmonary disease? Lancet 2017, 390:980-987.

7. Stockley RA, Halpin DMG, Celli BR, Singh D: Chronic Obstructive Pulmonary Disease Biomarkers and Their Interpretation. Am J Respir Crit Care Med 2019, 199:1195-1204.

8. Moon JY, Leitao Filho FS, Shahangian K, Takiguchi H, Sin DD: Blood and sputum protein biomarkers for chronic obstructive pulmonary disease (COPD). Expert Rev Proteomics 2018, 15:923-935.

9. Liu X, Qu J, Xue W, He L, Wang J, Xi X, Liu X, Yin Y, Qu Y: Bioinformatics-based identification of potential microRNA biomarkers in frequent and non-frequent exacerbators of COPD. Int J Chron Obstruct Pulmon Dis 2018, 13:1217-1228.

10. Stolzenburg LR, Harris A: The role of microRNAs in chronic respiratory disease: recent insights. Biol Chem 2018, 399:219-234.

11. Morrow JD, Cho MH, Hersh CP, Pinto-Plata V, Celli B, Marchetti N, Criner G, Bueno R, Washko G, Glass K, et al: DNA methylation profiling in human lung tissue identifies genes associated with COPD. Epigenetics 2016, 11:730-739. 
12. Busch R, Qiu W, Lasky-Su J, Morrow J, Criner G, DeMeo D: Differential DNA methylation marks and gene comethylation of COPD in African-Americans with COPD exacerbations. Respir Res 2016, 17:143.

13. Obeidat M, Zhou G, Li X, Hansel NN, Rafaels N, Mathias R, Ruczinski I, Beaty TH, Barnes KC, Paré PD, Sin DD: The genetics of smoking in individuals with chronic obstructive pulmonary disease. Respir Res 2018, 19:59.

14. Burkart KM, Sofer T, London SJ, Manichaikul A, Hartwig FP, Yan Q, Soler Artigas M, Avila L, Chen W, Davis Thomas S, et al: A Genome-Wide Association Study in Hispanics/Latinos Identifies Novel Signals for Lung Function. The Hispanic Community Health Study/Study of Latinos. Am J Respir Crit Care Med 2018, 198:208-219.

15. Yu B, Flexeder C, McGarrah RW, 3rd, Wyss A, Morrison AC, North KE, Boerwinkle E, Kastenmüller G, Gieger C, Suhre K, et al: Metabolomics Identifies Novel Blood Biomarkers of Pulmonary Function and COPD in the General Population. Metabolites 2019, 9.

16. Pinto-Plata V, Casanova C, Divo M, Tesfaigzi Y, Calhoun V, Sui J, Polverino F, Priolo C, Petersen H, de Torres JP, et al: Plasma metabolomics and clinical predictors of survival differences in COPD patients. Respir Res 2019, 20:219.

17. Brusselle G, Pavord ID, Landis S, Pascoe S, Lettis S, Morjaria N, Barnes N, Hilton E: Blood eosinophil levels as a biomarker in COPD. Respir Med 2018, 138:21-31.

18. Tinè M, Biondini D, Semenzato U, Bazzan E, Cosio MG, Saetta M, Turato G: Reassessing the Role of Eosinophils as a Biomarker in Chronic Obstructive Pulmonary Disease. J Clin Med 2019, 8.

19. Postma DS, Reddel HK, ten Hacken NH, van den Berge M: Asthma and chronic obstructive pulmonary disease: similarities and differences. Clin Chest Med 2014, 35:143-156.

20. George L, Brightling CE: Eosinophilic airway inflammation: role in asthma and chronic obstructive pulmonary disease. Ther Adv Chronic Dis 2016, 7:34-51.

21. Couillard S, Larivee P, Courteau J, Vanasse A: Eosinophils in COPD Exacerbations Are Associated With Increased Readmissions. Chest 2017, 151:366-373.

22. Tashkin DP, Wechsler ME: Role of eosinophils in airway inflammation of chronic obstructive pulmonary disease. Int $J$ Chron Obstruct Pulmon Dis 2018, 13:335-349.

23. Barnes NC, Sharma R, Lettis S, Calverley PM: Blood eosinophils as a marker of response to inhaled corticosteroids in COPD. Eur Respir J 2016, 47:1374-1382.

24. Wu HX, Zhuo KQ, Cheng DY: Peripheral Blood Eosinophil as a Biomarker in Outcomes of Acute Exacerbation of Chronic Obstructive Pulmonary Disease. Int J Chron Obstruct Pulmon Dis 2019, 14:3003-3015.

25. Couillard S, Larivée P, Courteau J, Vanasse A: Eosinophils in COPD Exacerbations Are Associated With Increased Readmissions. Chest 2017, 151:366-373.

26. Bélanger M, Couillard S, Courteau J, Larivée P, Poder TG, Carrier N, Girard K, Vézina FA, Vanasse A: Eosinophil counts in first COPD hospitalizations: a comparison of health service utilization. Int J Chron Obstruct Pulmon Dis 2018, 13:3045-3054.

27. Kaplan AG: Inhaled Corticosteroid Treatment in Chronic Obstructive Pulmonary Disease (COPD): Boon or Bane? J Am Board Fam Med 2020, 33:289-302.

28. Suissa S, Dell'Aniello S, Ernst P: Comparative Effects of LAMA-LABA-ICS vs LAMA-LABA for COPD: Cohort Study in Real-World Clinical Practice. Chest 2019.

29. Qi YJ, Sun XJ, Wang Z, Bin YF, Li YH, Zhong XN, Bai J, Deng JM, He ZY: Richness of sputum microbiome in acute exacerbations of eosinophilic chronic obstructive pulmonary disease. Chin Med J (Engl) 2020, 133:542-551.

30. Cheng SL, Lin CH: Effectiveness using higher inhaled corticosteroid dosage in patients with COPD by different blood eosinophilic counts. Int J Chron Obstruct Pulmon Dis 2016, 11:2341-2348.

31. Mortality GBD, Causes of Death C: Global, regional, and national age-sex specific all-cause and cause-specific mortality for 240 causes of death, 1990-2013: a systematic analysis for the Global Burden of Disease Study 2013. 
Lancet 2015, 385:117-171.

32. Patel JG, Coutinho AD, Lunacsek OE, Dalal AA: COPD affects worker productivity and health care costs. Int J Chron Obstruct Pulmon Dis 2018, 13:2301-2311.

33. Vos T, Flaxman AD, Naghavi M, Lozano R, Michaud C, Ezzati M, Shibuya K, Salomon JA, Abdalla S, Aboyans V, et al: Years lived with disability (YLDs) for 1160 sequelae of 289 diseases and injuries 1990-2010: a systematic analysis for the Global Burden of Disease Study 2010. Lancet 2012, 380:2163-2196.

34. DiSantostefano RL, Hinds D, Le HV, Barnes NC: Relationship between blood eosinophils and clinical characteristics in a cross-sectional study of a US population-based COPD cohort. Respir Med 2016, 112:88-96.

35. MacDonald MI, Osadnik CR, Bulfin L, Hamza K, Leong P, Wong A, King PT, Bardin PG: Low and High Blood Eosinophil Counts as Biomarkers in Hospitalized Acute Exacerbations of COPD. Chest 2019, 156:92-100.

36. Turato G, Semenzato U, Bazzan E, Biondini D, Tinè M, Torrecilla N, Forner M, Marin JM, Cosio MG, Saetta M: Blood Eosinophilia Neither Reflects Tissue Eosinophils nor Worsens Clinical Outcomes in Chronic Obstructive Pulmonary Disease. Am J Respir Crit Care Med 2018, 197:1216-1219.

37. Eltboli O, Mistry V, Barker B, Brightling CE: Relationship between blood and bronchial submucosal eosinophilia and reticular basement membrane thickening in chronic obstructive pulmonary disease. Respirology 2015, 20:667-670.

38. Kolsum U, Damera G, Pham TH, Southworth T, Mason S, Karur P, Newbold P, Singh D: Pulmonary inflammation in patients with chronic obstructive pulmonary disease with higher blood eosinophil counts. J Allergy Clin Immunol 2017, 140:1181-1184.e1187.

39. Rabe KF, Watz H, Baraldo S, Pedersen F, Biondini D, Bagul N, Hanauer G, Göhring UM, Purkayastha D, Román J, et al: Anti-inflammatory effects of roflumilast in chronic obstructive pulmonary disease (ROBERT): a 16-week, randomised, placebo-controlled trial. Lancet Respir Med 2018, 6:827-836.

40. Pascoe S, Locantore N, Dransfield MT, Barnes NC, Pavord ID: Blood eosinophil counts, exacerbations, and response to the addition of inhaled fluticasone furoate to vilanterol in patients with chronic obstructive pulmonary disease: a secondary analysis of data from two parallel randomised controlled trials. Lancet Respir Med 2015, 3:435-442.

41. Papi A, Bellettato CM, Braccioni F, Romagnoli M, Casolari P, Caramori G, Fabbri LM, Johnston SL: Infections and airway inflammation in chronic obstructive pulmonary disease severe exacerbations. Am J Respir Crit Care Med 2006, 173:1114-1121.

42. Dai MY, Qiao JP, Xu YH, Fei GH: Respiratory infectious phenotypes in acute exacerbation of COPD: an aid to length of stay and COPD Assessment Test. Int J Chron Obstruct Pulmon Dis 2015, 10:2257-2263.

43. Bafadhel M, McKenna S, Terry S, Mistry V, Reid C, Haldar P, McCormick M, Haldar K, Kebadze T, Duvoix A, et al: Acute exacerbations of chronic obstructive pulmonary disease: identification of biologic clusters and their biomarkers. $A m \mathrm{~J}$ Respir Crit Care Med 2011, 184:662-671.

44. Ni W, Bao J, Yang D, Xi W, Wang K, Xu Y, Zhang R, Gao Z: Potential of serum procalcitonin in predicting bacterial exacerbation and guiding antibiotic administration in severe COPD exacerbations: a systematic review and metaanalysis. Infect Dis (Lond) 2019, 51:639-650.

45. Ergan B, Şahin AA, Topeli A: Serum Procalcitonin as a Biomarker for the Prediction of Bacterial Exacerbation and Mortality in Severe COPD Exacerbations Requiring Mechanical Ventilation. Respiration 2016, 91:316-324.

46. Durmuş U, Doğan N, Pekdemir M, Yılmaz S, Yaka E, Karadaş A, Güney Pınar S: The value of lactate clearance in admission decisions of patients with acute exacerbation of COPD. Am J Emerg Med 2018, 36:972-976.

\section{Tables}

Table 1. Demographic data of the patients with AECOPD $(n=455)$ 


\begin{tabular}{|c|c|c|c|c|c|}
\hline & $\begin{array}{c}\text { NEOS-AECOPD } \\
(n=214)\end{array}$ & $\begin{array}{c}\text { MEOS-AECOPD } \\
(n=63)\end{array}$ & $\begin{array}{c}\text { SEOS-AECOPD } \\
(\mathrm{n}=178)\end{array}$ & $\begin{array}{l}\text { Statistical } \\
\text { values }\end{array}$ & $\mathrm{P}$ \\
\hline Sex (Male, \%) & 159 & 51 & 138 & 1.375 & 0.503 \\
\hline Age (years) & $71.2056 \pm 9.31175$ & $73.1429 \pm 9.89437$ & $70.2528 \pm 9.06961$ & 2.272 & 0.104 \\
\hline BMI & $21.908271 \pm 3.6468114$ & $22.739524 \pm 3.3535515$ & $22.285506 \pm 4.0060567$ & 1.329 & 0.266 \\
\hline Smoking & & & & 0.366 & 0.833 \\
\hline Non-smoking & 74 & 24 & 71 & & \\
\hline Ex-smoking & 56 & 11 & 36 & & \\
\hline current-smoking & 84 & 28 & 71 & & \\
\hline GOLD Stages & & & & 5.875 & 0.053 \\
\hline Stage I: mild ( $\geq 80 \%$ ) & 25 & 10 & 21 & & \\
\hline $\begin{array}{c}\text { Stage II: moderate } \\
(50-79 \%)\end{array}$ & 62 & 24 & 59 & & \\
\hline $\begin{array}{c}\text { Stage III: severe (30- } \\
49 \%)\end{array}$ & 54 & 17 & 52 & & \\
\hline $\begin{array}{l}\text { Stage IV: very severe } \\
(<30 \%) \text { without } \\
\text { respiratory failure }\end{array}$ & 17 & 4 & 13 & & \\
\hline Respiratory failure & 56 & 8 & 33 & & \\
\hline $\begin{array}{l}\text { Underlying diseases/ } \\
\text { Comorbidities }\end{array}$ & & & & & \\
\hline Pneumothorax & 2 & 0 & 3 & 1.317 & 0.518 \\
\hline Pleural effusion (PE) & 11 & 0 & 6 & 3.684 & 0.158 \\
\hline $\begin{array}{l}\text { Community acquired } \\
\text { Pneumonia (CAP) }\end{array}$ & 96 & 26 & 74 & 0.525 & 0.769 \\
\hline Cor pulmonale & 43 & 6 & 26 & 4698 & 0095 \\
\hline $\begin{array}{c}\text { Coronary artery } \\
\text { disease (CAD) }\end{array}$ & 46 & 12 & 27 & 2.567 & 0.277 \\
\hline Hypertension & 80 & 21 & 73 & 1.288 & 0.525 \\
\hline $\mathrm{T} 2 \mathrm{DM}$ & 39 & 14 & 20 & 5.595 & 0.061 \\
\hline Atrial fibrillation (Af) & 11 & 3 & 5 & 1.383 & 0.501 \\
\hline $\begin{array}{l}\text { Connective tissue } \\
\text { disease (CTD) }\end{array}$ & 0 & 0 & 4 & 6.280 & 0.043 \\
\hline Metabolic acidosis & 35 & 12 & 20 & 3.116 & 0.211 \\
\hline
\end{tabular}

Table 2. Clinical features and laboratory data of the patients with AECOPD $(n=455)$ 


\begin{tabular}{|c|c|c|c|c|c|}
\hline & $\begin{array}{c}\text { NEOS-AECOPD } \\
(\mathrm{n}=214)\end{array}$ & $\begin{array}{c}\text { MEOS-AECOPD } \\
(\mathrm{n}=63)\end{array}$ & $\begin{array}{c}\text { SEOS-AECOPD } \\
(\mathrm{n}=178)\end{array}$ & $\begin{array}{c}\text { Statistical } \\
\text { values }\end{array}$ & $\mathrm{P}$ \\
\hline Fever (n) & 29 & 0 & 7 & 18.622 & 0.000 \\
\hline WBCs $\left(\times 10^{9} / \mathrm{L}\right)$ & $9.127710 \pm 4.0336889$ & $6.900000 \pm 3.3279302$ & $7.207528 \pm 2.5874116$ & 19.396 & 0.000 \\
\hline NS $\left(\times 10^{9} / \mathrm{L}\right)$ & $7.495327 \pm 6.4450553$ & $4.818889 \pm 3.1813231$ & $4.869382 \pm 2.1464153$ & 17.341 & 0.000 \\
\hline $\begin{array}{l}\text { Lymphocytes } \\
\left.\qquad \times 10^{9} / \mathrm{L}\right)\end{array}$ & $1.365327 \pm 0.9051292$ & $1.470476 \pm 0.6305692$ & $1.479326 \pm 0.5649365$ & 1.253 & 0.287 \\
\hline $\operatorname{EOS}\left(\times 10^{9} / \mathrm{L}\right)$ & $0.059393 \pm 0.0508252$ & $0.156032 \pm 0.0493683$ & $0.502022 \pm 0.5874828$ & 71.795 & 0.000 \\
\hline NS\% & $78.291729 \pm 37.4499608$ & $67.818413 \pm 9.5222841$ & $66.115618 \pm 10.2687442$ & 11.008 & 0.000 \\
\hline Lymphocytes\% & $16.887710 \pm 9.9761204$ & $23.018254 \pm 7.9939971$ & $21.994551 \pm 8.6718274$ & 19.520 & 0.000 \\
\hline EOS \% & $0.747570 \pm .6408311$ & $2.359206 \pm .3470767$ & $6.685562 \pm 5.0527810$ & 170.959 & 0.000 \\
\hline NLR & $7.945654 \pm 9.5498819$ & $4.191587 \pm 5.7973724$ & $3.699944 \pm 2.0624385$ & 19.620 & 0.000 \\
\hline RBCs & $4.416748 \pm 0.7819829$ & $4.535873 \pm 0.5766411$ & $4.525337 \pm 0.6074892$ & 1.474 & 0.230 \\
\hline \multicolumn{6}{|l|}{$\left(\times 10^{12} / \mathrm{L}\right)$} \\
\hline $\mathrm{Hb}(\mathrm{g} / \mathrm{L})$ & $132.35514 \pm 17.8379520$ & $135.31746 \pm 14.2464771$ & $134.23118 \pm 18.3276071$ & 0.944 & 0.390 \\
\hline Hct $(\%)$ & $40.175467 \pm 5.3567446$ & $40.890476 \pm 3.9642643$ & $40.921348 \pm 4.3530357$ & 1.337 & 0.264 \\
\hline PLTs $\left(\times 10^{9} / \mathrm{L}\right)$ & $203.242991 \pm 76.3426106$ & $186.555556 \pm 60.5199988$ & $201.404494 \pm 73.6012649$ & 1.301 & 0.273 \\
\hline PCT (ng/ml) & $0.218766 \pm 0.7493592$ & $0.139349 \pm 0.6293068$ & $0.065798 \pm 0.0805874$ & 3.545 & 0.030 \\
\hline CRP (mg/ml) & $27.364953 \pm 40.8671745$ & $16.965079 \pm 28.8966242$ & $17.563483 \pm 29.1130111$ & 4.563 & 0.011 \\
\hline $\begin{array}{c}\text { ESR } \\
(\mathrm{mm} / \text { first hour })\end{array}$ & $24.635514 \pm 20.9070793$ & $19.714286 \pm 20.5578872$ & $19.932584 \pm 19.6588404$ & 3.095 & 0.046 \\
\hline \multicolumn{6}{|l|}{ ABG } \\
\hline PH & $7.412682 \pm 0.2815835$ & $7.431905 \pm 0.0361385$ & $7.429663 \pm 0.0477150$ & 0.458 & 0.633 \\
\hline $\begin{array}{c}\mathrm{PaCO} 2 \\
(\mathrm{mmHg})\end{array}$ & $43.564486 \pm 13.6961751$ & $40.746032 \pm 6.5302479$ & $42.502247 \pm 9.1182623$ & 1.600 & 0.203 \\
\hline $\mathrm{PaO} 2$ (mmHg) & $82.598131 \pm 28.5118738$ & $79.777778 \pm 19.4492262$ & $78.938202 \pm 21.5099925$ & 1.115 & 0.329 \\
\hline OI (mmHg) & $343.990654 \pm 97.8380856$ & $347.984127 \pm 72.4307215$ & $346.898876 \pm 85.3106050$ & 0.075 & 0.928 \\
\hline $\mathrm{AB}(\mathrm{mmol} / \mathrm{L})$ & $28.489252 \pm 6.1881931$ & $26.898413 \pm 3.8558080$ & $27.778090 \pm 4.0188008$ & 2.582 & 0.077 \\
\hline $\mathrm{SB}(\mathrm{mmol} / \mathrm{L})$ & $27.662150 \pm 3.4513272$ & $26.823810 \pm 2.7911562$ & $27.159551 \pm 2.3971602$ & 2.505 & 0.083 \\
\hline $\mathrm{AG}(\mathrm{mmol} / \mathrm{L})$ & $12.104299 \pm 4.3290494$ & $12.295238 \pm 4.0810905$ & $9.645506 \pm 5.4451873$ & 14.966 & 0.000 \\
\hline $\begin{array}{l}\text { Serum Na } \\
(\mathrm{mmol} / \mathrm{L})\end{array}$ & $137.636916 \pm 5.0665516$ & $139.073016 \pm 4.0107198$ & $138.876966 \pm 4.4745202$ & 4.308 & 0.014 \\
\hline $\begin{array}{l}\text { Serum K } \\
(\mathrm{mmol} / \mathrm{L})\end{array}$ & $3.896262 \pm 0.4741605$ & $3.965556 \pm 0.3839051$ & $4.016742 \pm 0.0303221$ & 3.737 & 0.025 \\
\hline $\begin{array}{l}\text { Serum Ca } \\
(\mathrm{mmol} / \mathrm{L})\end{array}$ & $2.223738 \pm .1488486$ & $2.242222 \pm 0.1972917$ & $2.268483 \pm 0.1781526$ & 3.452 & 0.033 \\
\hline $\begin{array}{l}\text { Serum Mg } \\
(\mathrm{mmol} / \mathrm{L})\end{array}$ & $0.839720 \pm 0.0951594$ & $0.886032 \pm 0.1219669$ & $0.870730 \pm 0.1146699$ & 6.539 & 0.002 \\
\hline ALB (g/L) & $37.813551 \pm 4.3179452$ & $37.894127 \pm 3.9404780$ & $38.765169 \pm 4.1056968$ & 2.703 & 0.068 \\
\hline BUN (mmol/L) & $6.562897 \pm 2.5492516$ & $6.708571 \pm 2.3177268$ & $5.946236 \pm 1.8600346$ & 4.539 & 0.011 \\
\hline $\mathrm{Cr}(\mu \mathrm{mol} / \mathrm{L})$ & $72.299533 \pm 27.8074238$ & $73.471587 \pm 23.2868408$ & $73.812865 \pm 20.2982227$ & 0.196 & 0.822 \\
\hline $\mathrm{ALT}(\mathrm{U} / \mathrm{L})$ & $24.677570 \pm 38.0325258$ & $26.728571 \pm 43.6346209$ & $21.196629 \pm 22.0215762$ & 0.836 & 0.434 \\
\hline AST (U/L) & $27.925234 \pm 43.1549672$ & $28.396825 \pm 45.6301894$ & $23.117978 \pm 16.9972617$ & 1.030 & 0.358 \\
\hline IBIL $(\mu \mathrm{mol} / \mathrm{L})$ & $6.397243 \pm 3.3865077$ & $6.846032 \pm 3.6854914$ & $5.984831 \pm 2.8904372$ & 1.826 & 0.162 \\
\hline DBIL ( $\mu \mathrm{mol} / \mathrm{L})$ & $5.060234 \pm 3.0660336$ & $4.557143 \pm 2.8291521$ & $4.007865 \pm 1.7511723$ & 8.000 & 0.000 \\
\hline RBG (mmol/L) & $6.878692 \pm 2.8710151$ & $6.809048 \pm 2.3441855$ & $6.508539 \pm 1.9257216$ & 1.136 & 0.322 \\
\hline LHS (day) & $9.9112 \pm 4.90727$ & $9.2381 \pm 4.02698$ & $8.6180 \pm 3.80605$ & 4.233 & 0.015 \\
\hline \multicolumn{4}{|c|}{ Mechanical Ventilation (MV) } & 8.671 & 0.013 \\
\hline $\begin{array}{l}\text { Non- } \\
\text { ventilation(n) }\end{array}$ & 187 & 59 & 170 & & \\
\hline NIPPV(n) & 26 & 4 & 8 & & \\
\hline $\operatorname{IPPV}(\mathrm{n})$ & 1 & 0 & 0 & & \\
\hline
\end{tabular}

Abbreviations: WBCs: White blood cells; NS: Neutrophils; NLR: Neutrophils-to-lymphocytes ratio; EOS: Eosinophils; RBCs: Red blood cells; PLTs: Platelets; Hb: Hemoglobin; CRP: C-reaction protein; ESR: Erythrocyte sedimentation rate; ABG: Air blood gas; OI: Oxygen index; AB: Actual base; SB: Standard base; AG: Anion gap; Na+: Sodium; K+: Potassium; $\mathrm{Ca}^{2+}$ : Calcium; $\mathrm{Mg}^{2+}$ : Magnesium; Cr: Creatinine; BUN: Blood urea nitrogen; ALB: Albumin; ALT: Alanine aminotransferase; AST: Aspartate aminotransferase; IBIL: Indirect bilirubin; DBIL: Direct bilirubin; PCT: Procalcitonin; RBG: Random blood glucose; LHS: Length of hospital stay; MV: Mechanical Ventilation; NIPPV: Non-invasive positive pressure ventilation; IPPV: Invasive positive pressure ventilation.

Table 3. Multiple logistic regression analysis of independent factors associated with blood eosinophils in AECOPD ( $n=455)$ 


\begin{tabular}{ccccccc}
\hline & Estimate & S.E & Wals & df & Sig. & 95\% C.I. \\
\hline Lymphocytes\% & -0.238 & 0.037 & 41.127 & 1 & 0.000 & $-0.311 \sim-0.165$ \\
NS\% & -0.254 & 0.041 & 38.431 & 1 & 0.000 & $-0.334 \sim-0.174$ \\
PCT (ng/ml) & -1.494 & 0.355 & 17.739 & 1 & 0.000 & $-2.189 \sim-0.799$ \\
AG (mmol/L) & -0.099 & 0.022 & 19.587 & 1 & 0.000 & $-0.142 \sim-0.055$ \\
\hline
\end{tabular}

Table 4. The correlations between EOS counts/EOS \% in blood and lymphocytes\%, NS\%, PCT, AG in AECOPD patients

\begin{tabular}{cccccc}
\hline & & Lymphocytes $\%$ & NS\% & PCT & AG \\
\hline EOS counts $\left(\times 10^{9} / \mathrm{L}\right)$ & $\mathrm{R}$ & 0.221 & -0.365 & -0.214 & -0.184 \\
& $\mathrm{P}$ & 0.000 & 0.000 & 0.000 & 0.000 \\
EOS $\%$ & $\mathrm{R}$ & 0.335 & -0.481 & -0.262 & -0.222 \\
& $\mathrm{P}$ & 0.000 & 0.000 & 0.000 & 0.000 \\
\hline
\end{tabular}

\section{Figures}

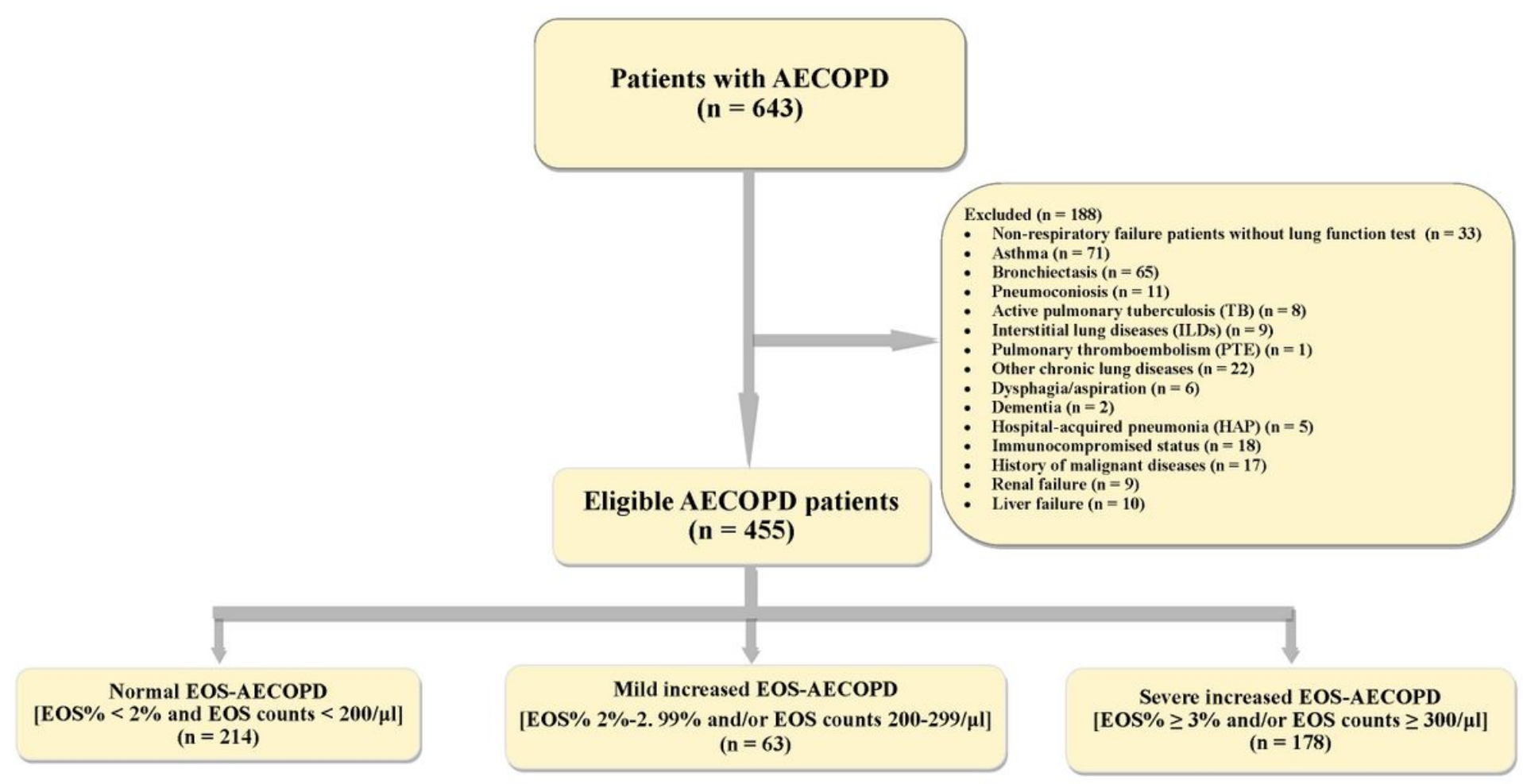

Figure 1

The flow diagram of the study. 